\title{
Homoparentalidade: um diálogo com a produção acadêmica no Brasil
}

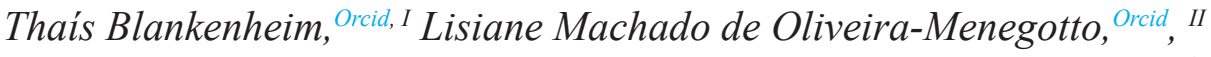 \\ Denise Regina Quaresma da Silva Orcid, II, $\star$ \\ ${ }^{I}$ Pontifícia Universidade Católica do Rio Grande do Sul, Porto Alegre, RS, Brasil \\ ${ }^{I I}$ Universidade Feevale, Vila Nova, Novo Hamburgo, RS, Brasil
}

\section{Resumo}

Este estudo objetiva discutir a produção acadêmica no campo do conhecimento científico brasileiro sobre a homoparentalidade. Foi realizada uma pesquisa nas bases de dados do Scielo e do Google Acadêmico, utilizando o descritor "homoparentalidade". Verificamos que é recente e incipiente a discussão sobre a temática da homoparentalidade no Brasil, pois foram encontrados somente 19 artigos cientificos publicados no periodo de 2005 a 2013. O termo é bastante novo, em termos históricos, e parece estar adentrando o campo científico recentemente. A psicologia é a área de atuação que mais pesquisa sobre homoparentalidade. Analisando os resultados das pesquisas existentes, percebemos que o tema em questão ainda é muito cercado por preconceitos, rótulos e estigmas.

Palavras-chave: homoparentalidade; psicologia; família homoparental.

\section{Homoparenthood: a dialogue with the academic production in Brazil}

\begin{abstract}
This study aims to discuss academic production in the Brazilian scientific knowledge field about homoparenthood. A research was conducted in the Scielo and Google Scholar databases, using the descriptor "homoparenthood". We find that is new and incipient discussion on the theme of homoparenthood in Brazil, as found only 19 papers published in the period 2005 to 2013. The term is fairly new, in historical terms, and seems to be pushing into the scientific field recently. The sphere of activity more research on homoparenthood is psychology. Analyzing the results from the researches, it is seen that the subject in question is still surrounded by preconceptions, labels and stigmas.
\end{abstract}

Keywords: homoparenthood; psychology; homoparental family.

\section{Introdução}

A sexualidade ainda é um dos assuntos mais difíceis de ser pensado e discutido nos dias atuais. Cercada por preconceitos, mitos e tabus, ela se torna ainda mais complexa quando a discussão remete à homossexualidade, vista ainda por muitos, equivocadamente, como um desvio da sexualidade.

Historicamente, por volta de 1870 , a medicina começou a constituir a homossexualidade como objeto de análise médica. A partir deste momento, vieram muitas intervenções e controles na busca por uma sexualidade dita normal (FOUCAULT, 1996).

A homossexualidade, considerada inicialmente no meio científico como transtorno, começou a ser pensada de maneira diferente no Brasil quando, em 1985, o Conselho Federal de Medicina (CFM) retirou-a da condição de transtorno sexual (ARAÚJO; OLIVEIRA, 2008). Nessa mesma perspectiva, em 1999, o Conselho Federal de Psicologia estabeleceu a Resolução CFP no 001/99, que afirma que a homossexualidade não constitui doença, nem distúrbio ou perversão. Junto a isso, colocou diretrizes para nortear a prática dos profissionais, no sentido de eliminar procedimentos que ofereciam a "cura" de alguma orientação sexual que estivesse fora do padrão heterossexual (CONSELHO FEDERAL DE PSICOLOGIA, 1999).

\footnotetext{
^Endereço para correspondência: Universidade Feevale, Programa de Pós-Graduação em Diversidade Cultural e Inclusão Social. ERS-239, 2755 - Centro. Novo Hamburgo, RS - Brasil. CEP: 93600000. E-mail: thaisblankenheim@ hotmail.com, lisianeoliveira@feevale.br, denisequaresma@feevale.br
}

Ainda assim, o preconceito e a reprovação em relação aos homossexuais continuam vigentes no Brasil em pessoas ou grupos como, por exemplo, aqueles ligados a algumas religiões fundamentalistas cristãs. De acordo com Brandão (2002), o Catolicismo ainda reprova a relação entre pessoas do mesmo sexo e essa reprovação recebe um forte incremento de grupos religiosos com presença política importante em todos os níveis de tomada de decisão, sobretudo as pressões da Bancada Evangélica do Congresso Nacional brasileiro. Exemplificamos essa atuação no campo escolar com os acontecimentos de 2008, quando os Ministérios da Saúde e da Educação lançaram um projeto intitulado Escola sem Homofobia para responder às dificuldades dos professores em lidar com esse assunto. Após os ataques da bancada religiosa no Congresso Nacional, em maio de 2011, a presidente Dilma Roussef cancelou o projeto e os Ministérios da Saúde e da Educação foram instruídos a suspender todas as atividades relacionadas ao projeto.

Entretanto, com o fato de que essas questões estão ganhando maior visibilidade social nos dias de hoje, várias reivindicações aparecem no cenário atual, de modo que as pessoas clamam pelo direito do exercício de formas inéditas de paternidade e maternidade. Em relação aos casais homossexuais, essas reivindicações provocam resistência, tanto no campo da sociedade, quanto no campo teórico (PERELSON, 2006).

Várias ideias preconceituosas, como afirmar que a criança não poderia se desenvolver plenamente sem um pai e uma mãe, definidos pelo sexo biológico como sendo um homem e uma mulher, ou que as crianças criadas por 
homossexuais seriam influenciadas a serem homossexuais também, começam a ser desmistificadas. Zambrano et al. (2006) afirmam que há inexistência de diferenças em relação à habilidade para cuidar dos filhos e à capacidade parental de pessoas heterossexuais e homossexuais. Além disso, apontam não haver diferenças significativas entre o desenvolvimento das crianças criadas por famílias heterossexuais quando comparadas às inseridas em famílias homossexuais.

Nesse sentido, a família homoparental é uma das múltiplas configurações familiares com que nos deparamos atualmente, sendo que esta não é uma configuração familiar nova, pois já há muito tempo homossexuais solteiros ou em parceria criam crianças. O que é novo é a nomeação e a visibilidade social, que passam a alcançar na década de 1960. Isso foi possível a partir de movimentos sociais, com o objetivo de terem reconhecimento do seu desejo de serem pais e mães (MARTINEZ, 2013).

Roudinesco (2003) historiciza a construção da família, sob as perspectivas psíquica, política e econômica, traçando seu percurso desde a antiguidade até a pós-modernidade. A autora afirma que a possibilidade recente e atual de formar uma família sem a necessidade e obrigação do coito sexual, juntamente com o crescente envolvimento dos homens na criação dos filhos, aponta para a necessidade de repensarmos tanto a família quanto a instituição do casamento. Essas e outras transformações fazem com que a instituição familiar seja acessível também aos homossexuais, que, historicamente, sempre foram excluídos dessa possibilidade. Assim, em 1965, gays e lésbicas passam a reivindicar o direito à paternidade e maternidade, transgredindo uma ordem moral que já durava mais de dois mil anos (ROUDINESCO, 2003).

Roudinesco (2003) também evidencia que, mesmo com o declínio da família de formato tradicional, essa instituição não está se dissolvendo, mas sim se organizando de uma maneira diferente e nova, horizontal e em redes. Assim, nas novas configurações familiares, como é o caso da família homoparental, também se garante a reprodução das gerações, a partir das possibilidades de adoção e das novas tecnologias reprodutivas.

Nesse contexto, a principal conquista, em termos legais, ocorreu no dia 05 de maio de 2011, momento em que foi aprovado pelo Supremo Tribunal Federal o reconhecimento da união homoafetiva como entidade familiar, podendo, assim, consolidar a relação por meio da união estável no Brasil. Com essa decisão, os homossexuais passaram a ter alguns direitos que por muito tempo eram exclusivos dos heterossexuais, tais como: direito de comunhão parcial de bens; direito à pensão alimentícia no caso de separação; direito à pensão do INSS em caso da morte do parceiro; direito de colocar o companheiro como dependente em Planos de Saúde; direito a mencionar o parceiro como dependente ao declarar o Imposto de Renda; e o direito a adotar crianças, não tendo, agora, preferência a casais heterossexuais (COSTA; FILHO, 2015).
Mesmo com essa determinação legal, podemos verificar, ainda, resistências oriundas de uma posição política conservadora dos estatutos que regem a família, principalmente apoiada pela bancada religiosa. No mês de julho de 2015, foi aprovado pela Câmara Legislativa do Distrito Federal o Projeto de Lei $n^{\circ} 173 / 2015$, que ficou conhecido como Estatuto da Família do DF, que classifica como entidade familiar "o núcleo social formado a partir da união entre um homem e uma mulher". Especialistas garantem que mesmo que a iniciativa seja inconstitucional, já que afronta uma decisão do Supremo Tribunal Federal de 2011, foi aprovada como Projeto de Lei e, se assim for, também determinará que os currículos do ensino fundamental e médio devam incluir a disciplina Educação para a família, embasada na ideia da união somente entre homem e mulher (CONSELHO FEDERAL DE PSICOLOGIA, 2015).

Nessa assertiva, levando em conta a importância da discussão sobre essas questões na atualidade, esse artigo propõe uma revisão sistemática da produção científica de artigos publicados no Brasil sobre o tema da homoparentalidade, com busca realizada nas bases de dados do SciELO e do Google Acadêmico, com o uso do descritor homoparentalidade. Além disso, pretende-se analisar quais são as áreas de conhecimento que estão se ocupando desse assunto e quais os contextos e outros temas que estão sendo relacionados a ele.

\section{Procedimentos metodológicos}

A presente pesquisa, de caráter qualitativo e de cunho bibliográfico, é definida como estado da arte e objetiva mapear e discutir a produção acadêmica no campo do conhecimento científico brasileiro sobre a homoparentalidade, examinando aspectos e dimensões que vêm sendo destacados nestas publicações. As revisões bibliográficas são reconhecidas por uma metodologia de caráter inventariante e descritivo da produção acadêmica e científica sobre o tema que se propõem a investigar, a partir de categorias e facetas que se caracterizam enquanto tais em cada trabalho e no conjunto deles, sob os quais o fenômeno passa a ser analisado (FERREIRA, 2002).

Para o presente estudo, foi realizada uma busca em revistas científicas on-line de acesso gratuito, disponíveis nas redes de periódicos SciELO e Google acadêmico, com o uso do descritor "homoparentalidade". Essa pesquisa foi realizada no mês de abril de 2015 e não foi delimitado um período de busca da publicação dos artigos, para possibilitar o entendimento do momento no qual se inicia a discussão sobre a homoparentalidade no âmbito científico.

$\mathrm{Na}$ análise de alguns indicadores bibliométricos, verificamos o número de trabalhos publicados por ano, as palavras chaves mais recorrentes nas publicações elencadas e as principais áreas em que os artigos foram publicados, buscando descrever o cenário nacional das pesquisas sobre o tema abordado.

Os critérios de inclusão utilizados foram: artigos completos ou de revisão (excluindo os resumos de comunicações em congressos, as correções, as reimpressões e as notícias) que abordavam especificamente as famílias 
homoparentais e artigos publicados em língua portuguesa e no Brasil, com o intuito de verificar a produção científica a respeito da homoparentalidade no país. Na continuação, os artigos encontrados são atentamente lidos e examinados para a análise de conteúdo. Para a análise qualitativa, os 19 artigos encontrados foram categorizados utilizando o método proposto por Ruiz-Olabuénaga (2003). Após minuciosa leitura, analisam-se fenômenos que giram em torno dos focos de interesse da investigação. Ademais, o processo de análise dos dados se propôs a encontrar as proximidades e as similaridades dos diferentes textos, formando um texto de investigação.

\section{Discussão dos resultados: um panorama da publicação de artigos sobre homoparentalidade no Brasil}

$\mathrm{Na}$ busca realizada, foram encontrados 19 artigos publicados entre os anos de 2005 a 2013 que contêm a palavra homoparentalidade em seu título e/ou nas palavras-chave. Apresentamos na tabela a seguir, as produções encontradas por ano e por quantidade de publicação:

\begin{tabular}{|cc}
\multicolumn{2}{c}{ Tabela 1: Produções por ano e quantidade } \\
\hline Ano de publicação & Número de artigos \\
\hline 2005 & 1 \\
2006 & 4 \\
2007 & 0 \\
2008 & 2 \\
2009 & 1 \\
2010 & 1 \\
2011 & 1 \\
2012 & 4 \\
2013 & 5 \\
\hline
\end{tabular}

Esse resultado demonstra o quanto é escassa a discussão científica sobre esse tema, com uma concentração maior de publicações entre os anos de 2012 e 2013. Além disso, pode-se verificar o quanto o assunto em questão é recente, pois a primeira publicação encontrada data do ano de 2005, ou seja, os estudos científicos no Brasil sobre a homoparentalidade são recentes e se encontram em baixa escala (Tabela 1).

Contudo, é importante atentarmos para um fator que pode estar relacionado a esse resultado. Tal fator refere-se ao uso do descritor "homoparentalidade", que foi utilizado na busca dos artigos. Acreditamos que a baixa incidência da temática nas publicações esteja vinculada à recente denominação dada ao fenômeno em questão. $\mathrm{O}$ termo não foi criado num contexto científico, e sim social, pela Association des Parents et Futurs Parents Gays et Lesbiens (APGL), na França. A APGL, que é uma das principais associações homoparentais do mundo. Esta foi criada em 1986 e propõe atividades de informação, de compartilhamento de experiências e de serviços profissionais para famílias homoparentais e para futuros pais e mães (APGL, 2017). Sendo assim, pontuamos que o termo é bastante novo em termos históricos e parece estar adentrando o campo científico recentemente.

Analisando as áreas das publicações (Tabela 2), verificamos que a ciência que mais pesquisa sobre homoparentalidade é a Psicologia, comumente com viés teórico da Psicanálise, com onze publicações, seguida pela Antro- pologia, com três. Outras áreas que aparecem com uma publicação cada são o Direito, as Ciências Sociais, a Comunicação, a Educação e as Ciências Sociais, Psicanálise e Psicologia reunidas num mesmo artigo. Assim, foram organizados na tabela 2 os artigos por área do conhecimento:

Tabela 2: Produções por área do conhecimento e quantidade Áreas das publicações Número de artigos

\begin{tabular}{|cc|}
\hline Psicologia/Psicanálise & 11 \\
\hline Antropologia & 3 \\
Ciências sociais & 1 \\
Direito & 1 \\
Comunicação & 1 \\
Educação & 1 \\
Ciências & 1 \\
\hline Sociais/Psicanálise/Psicologia & \\
\hline
\end{tabular}

De modo convergente, nossos dados encontrados corroboram os dados da pesquisa de Zambrano et al. (2006), que apontam que a imensa maioria das pesquisas empíricas publicadas é realizada na área da Psicologia. Além disso, a grande parte das considerações utilizadas por diferentes profissionais que estudam esse tema está apoiada nos princípios teóricos da Psicanálise.

Foram analisadas, também, as palavras-chave dos artigos, para verificar as principais temáticas envolvidas e relacionadas ao assunto pelos autores, conforme a tabela 3 , a seguir.

\begin{tabular}{cc}
\multicolumn{2}{c}{ Tabela 3: Produções por palavras-chave recorrentes } \\
\hline $\begin{array}{c}\text { Palavras-chave mais } \\
\text { recorrentes }\end{array}$ & Número de artigos \\
\hline Família & 10 \\
Adoção & 6 \\
\hline $\begin{array}{c}\text { Filiação/Funções parentais/ } \\
\text { Parentalidade/Papeis parentais }\end{array}$ & 5 \\
\hline
\end{tabular}

Após a incidência maior, que é da própria palavra "homoparentalidade", que aparece em quase todas as palavras-chave, pode-se encontrar a presença da palavra "família" em dez artigos. Outras temáticas frequentemente mencionadas e relacionadas ao assunto principal são: a adoção, presente em seis artigos, e as questões de filiação/funções parentais/parentalidade/papeis parentais, presentes em cinco artigos.

Podemos verificar, assim, que a discussão sobre o que é família e sobre suas novas configurações na atualidade geralmente acompanha o tema da homoparentalidade nas publicações em questão. A adoção ainda é o meio mais utilizado para a formação dessas famílias, mesmo que, a partir da tecnologia reprodutiva, muitos casais tenham recorrido a técnicas de fecundação como alternativa. A partir da possibilidade de formação familiar, iniciam-se, também, as reflexões sobre as funções e papeis parentais, sobre a própria parentalidade e questões de filiação nesse contexto.

\section{Contextos estudados e considerações existentes}

A partir da apresentação e discussão sobre o panorama geral dos artigos publicados, verificamos, também, os contextos em que estão inseridas as pesquisas e as con- 
siderações finais dos autores. Assim, apresentaremos na análise dos artigos, os pontos principais desses aspectos em cada uma das publicações.

Iniciaremos a análise pelo artigo "Produção científica sobre adoção por casais homossexuais no contexto brasileiro" (CECILIO; SCORSOLINI-COMIN; SANTOS, 2013), que também se ocupou em fazer um levantamento sobre as publicações existentes nessa temática, mais especificamente sobre homoparentalidade adotiva. Para isso, os autores realizaram uma revisão sistemática da literatura científica nacional nas bases LILACS, PePSIC, SciELO e Portal Nacional BVS Brasil em Saúde, de 2000 a 2010, de modo que encontraram dez estudos. Neles, puderam verificar a presença de entraves na busca pela legitimização da adoção por casais homossexuais, entre eles o estigma de que "os filhos adotivos sofreriam prejuízos na construção de suas identidades, ocasionando possíveis desvios de personalidade pela falta de referência do gênero oposto" (CECILIO; SCORSOLINI-COMIN; SANTOS, 2013, p. 514). Ademais, as publicações analisadas nesse artigo ressaltam as especificidades das famílias homoafetivas no que diz respeito ao processo de reconhecimento legal e social, além da verificação do quanto esse tipo de adoção ainda é estigmatizado e alvo de preconceitos. Os autores apontam para a escassez de estudos sobre essa temática, que recentemente tornou-se visível nas ciências humanas.

O artigo "A adoção de crianças no contexto da homoparentalidade" (ARAÚJO; OLIVEIRA, 2008) teve como objetivo apreender e comparar como os universitários concluintes dos cursos de Direito e de Psicologia representam a adoção de crianças por casais homossexuais. Como enfoque teórico e metodológico, os autores utilizaram-se da "Teoria das Representações Sociais (TRS), considerando que, por constituírem um processo dinâmico, situado na articulação entre o social e o psicológico, as RS permitem conhecer a formação do pensamento social" (ARAÚJO; OLIVEIRA, 2008, p. 43). A partir dessa pesquisa, chegou-se à consideração de que tanto para os concluintes dos cursos de Psicologia quanto para os de Direito, a homossexualidade está ancorada juntamente à crença de que a AIDS é uma doença de gays. Além disso, a ideia que os participantes da pesquisa têm sobre a adoção de crianças por casais homossexuais é, sutil ou flagrantemente, preconceituosa, partindo da premissa de que esse tipo de adoção poderia ocasionar danos biopsicossociais à criança inserida no contexto. Ainda, os autores apontaram que a forma de conceber a estrutura familiar no modelo tradicional de orientação heterossexual provavelmente é um fator que influencia diretamente a concepção contrária à adoção de crianças por casais homossexuais.

Já o artigo "A homoparentalidade em questão: a voz de gays e lésbicas com filhos" (SANTOS; BRUNS, 2006) foi desenvolvido a partir de entrevistas com sujeitos envolvidos diretamente na questão da homoparentalidade: cinco homens e nove mulheres homossexuais com filho(s) biológico(s) e/ou adotivo(s). O objetivo do estudo foi compreender como mulheres e homens homossexuais entre 30 e 50 anos vivenciam a paternidade, a maternidade e/ou parentalidade e que significados lhe atribuem. Nesse sentido, os resultados demonstraram relatos de situações de preconceito em relação aos papeis sexuais dos participantes e a expressão da homossexualidade nas famílias de origem, no trabalho e entre amigos. Também, fica evidente a falta de referenciais de famílias homossexuais, sendo heterocêntrico o modelo de família presente no discurso dos indivíduos.

A publicação Famílias homoparentais: tão diferentes assim? (MARTINEZ, 2013) foi embasada em duas vinhetas clínicas, em que a autora apresenta e discute alguns dos temores sociais e fantasmáticos vinculados às famílias homoparentais, "entre eles o temor do apagamento da diferença entre os sexos e o receio de que a criança criada nesse contexto se torne homossexual" (MARTINEZ, 2013, p. 371). Em suas conclusões, que apontam a existência de rótulos e estigmas sobre o que é ser um bom pai ou uma boa mãe nesse contexto, o autor demonstra que os conflitos emocionais são o grande entrave para que os casais possam realizar um bom exercício da parentalidade e não a orientação sexual dos cuidadores.

$\mathrm{O}$ artigo "Um estudo sobre o exercício da parentalidade em contexto homoparental" (RODRIGUEZ; PAIVA, 2009) teve como objetivo apresentar o resultado de uma pesquisa realizada com dois casais que visou a investigar o exercício da homoparentalidade, focando as possíveis especificidades existentes no relacionamento parental homossexual, bem como compreender o olhar dos pais com relação a seus papeis parentais. Nesse estudo, percebeu-se que as famílias homoparentais se diferenciam de outras pelo preconceito sofrido, pela falta de apoio e aceitação das famílias de origem e círculos sociais.

Já o artigo "Uma família de mulheres: ensaio etnográfico sobre homoparentalidade na periferia de São Paulo" (MEDEIROS, 2006), além de tratar sobre a homoparentalidade, também discute questões sobre lesbianidade, refletindo sobre uma família recomposta homoparental feminina da periferia da cidade de São Paulo. Tendo uma base antropológica, a pesquisa aponta para a ideia de que a homossexualidade é concebida como algo tão construído socialmente quanto a heterossexualidade.

Na publicação "A parentalidade homossexual: uma exposição do debate psicanalítico no cenário francês atual" (PERELSON, 2006), apresenta-se um cenário do debate francês atual sobre a questão da homoparentalidade. Nela, são confrontados os pensamentos de cinco psicanalistas: Joël Dor e sua teorização sobre o papel da função paterna e da diferença anatômica entre os sexos na estruturação do sujeito; Pierre Legendre e sua articulação entre os campos do jurídico e do psíquico na inscrição do ser humano na ordem da filiação; Michel Tort e sua crítica às teorias de Legendre; Geneviève Delaisi de Parseval e sua proposta de uma definição mais ampla da família; e Sabine Prokhoris e a sua distinção entre sexuação e diferença dos sexos. A partir disso, buscou-se desmontar argumentos contrários à homoparentalidade $\mathrm{e}$ indicar a legitimidade da argumentação favorável a esse tipo de filiação. A autora chegou à consideração de que os últimos desenvolvimentos teóricos da psicanálise estão 
começando a reverter o seu paradigma a favor das reivindicações a respeito da filiação homossexual, até mesmo indicando "o quanto os heterossexuais dependem, tanto quanto os homossexuais, da possibilidade de exercer a arte da passagem cujas portas têm sido abertas por aqueles que conduziram à colocação em causa da diferença dos sexos" (PERELSON, 2006, p. 727).

O artigo "Que família? Provocações a partir da homoparentalidade" (VILHENA et al., 2011), construído conjuntamente por profissionais das áreas de Psicologia, Psicanálise e Ciências Sociais, tem como objeto de estudo as famílias homoparentais. A partir de uma pesquisa teórica, os autores constataram que o estigma da homossexualidade ainda é bastante sentido. A fundamentação desse trabalho sugere que sejam repensadas as identidades cristalizadas na atualidade e propõe que "se desconstruam estruturas já naturalizadas, através de um processo que sugere o questionamento de como tais estruturas chegaram a tal ponto. Propomos, desta forma, uma nova postura diante da vida e de si mesmo" (VILHENA et al., 2011, p. 1640).

Apresentando uma discussão sobre a categoria transgênero, o artigo "Papai é homem ou mulher? Questões sobre a parentalidade transgênero no Canadá e a homoparentalidade no Brasil" (SOUZA, 2013) problematiza a questão da parentalidade transgênero no Canadá e da parentalidade de travestis e transexuais no Brasil. Com base em dados de campo, a autora nos apresenta canadenses que lidam com constrangimentos sociais e culturais para poderem se manifestar afetiva, familiar, parental e sexualmente e analisa essas questões dialogando com o cenário brasileiro. Em seus questionamentos e considerações, está presente a possibilidade de uma existência discursiva, do ponto de vista acadêmico e político, das parentalidades transexual e travesti para além da homoparentalidade. Além disso, foram analisadas as concepções de paternidade, para compreender em que medida "elas reconfiguram as representações do pensamento ocidental ao performatizarem a parentalidade na sua relação com o gênero" (SOUZA, 2013, p. 397).

Já o artigo "Novas formas de parentalidade: do modelo tradicional à homoparentalidade" (RODRIGUEZ; GOMES, 2012) propõe uma reflexão sobre os modelos familiares e parentais presentes atualmente, com ênfase nas famílias homoparentais, tendo como base o referencial teórico da psicanálise de família e casal e estudos psicossociais. A principal consideração que as autoras chegam é sobre a aplicabilidade de uma ética relacional que reconheça a importância do vínculo na construção das novas formas de parentalidade, sem se limitar à égide biológica.

$\mathrm{O}$ artigo "Mitos atribuídos às pessoas homossexuais e o preconceito em relação à conjugalidade homossexual e a homoparentalidade" (FARIAS, 2010) faz um apanhado teórico sobre as ocorrências históricas que contribuíram para a visão que a sociedade tem hoje acerca da homossexualidade. Também discute alguns mitos relacionados à homossexualidade e à homoparentalidade, tais como: os homossexuais seriam todos promíscuos, a homossexualidade seria um distúrbio, os homossexuais não poderiam criar uma criança, pois ela seria influenciada a ser homos- sexual e os homossexuais tenderiam a abusar sexualmente de crianças. A autora aponta que essas crenças favorecem, na sociedade, a discriminação e o preconceito contra as pessoas homossexuais. Além disso, acabam dificultando uma visão positiva da sociedade e do meio jurídico em relação à homoparentalidade e a adoção por homossexuais.

No contexto dos debates sobre o direito dos homossexuais à adoção, encontra-se o artigo "Adoção por homossexuais - uma nova configuração familiar sob os olhares da psicologia e do direito" (FUTINO; MARTINS, 2006). Nesse estudo teórico, as autoras concluem que, no Brasil, os impedimentos para que homossexuais adotem crianças não estão no sentido legal, mas sim no âmbito moral, o que reflete uma sociedade que, embora esteja mudando seus conceitos, faz isso de maneira lenta.

Outro artigo que aborda a questão da adoção no âmbito jurídico é "A representação da homossexualidade nos discursos jurídicos sobre adoção homoparental" (FERNANDES, 2013). O estudo traz dados preliminares de uma pesquisa de mestrado em Ciências Sociais que trata das representações da homossexualidade a partir dos discursos jurídicos sobre adoção nas varas da infância, da juventude e do idoso da comarca da capital do Rio de Janeiro. Os resultados apontam duas estratégias na forma de lidar com a relação entre homossexualidade e parentalidade por parte dos envolvidos nos processos de adoção: a invisibilização das peculiaridades da adoção por casais homossexuais e certa idealização da homossexualidade, como se ela representasse vantagem em termos de amadurecimento pessoal do candidato à adoção.

Ainda no âmbito jurídico, encontra-se o artigo "Homoparentalidade: um direito em construção" (CUSTÓDIO, 2012), que é um estudo teórico que se propõe a analisar o movimento da sociedade brasileira no enfrentamento da homoparentalidade. Nele, constatou-se que os entraves legais à adoção por casais homossexuais e aspectos socioculturais envolvidos na questão ferem os princípios da igualdade e da dignidade da pessoa humana e, também, evidenciam uma grande carga de preconceito por parte da sociedade e, por reflexo, de seus legisladores. Além disso, mesmo ainda não existindo, em nosso país, uma legislação que discipline a união homoafetiva e adoção por esse núcleo familiar, destacou-se que a jurisprudência vem buscando implementar, por meio de decisões inovadoras, tais direitos. Por fim, o trabalho identifica alguns avanços e retrocessos existentes nas vias jurisprudencial e legislativa para a resolução de conflitos ligados à temática.

Já o artigo "Homoparentalidade: uma entre outras formas de ser família" (PASSOS, 2005) procura examinar, teoricamente, a homoparentalidade a partir das seguintes questões: o desejo do casal de ter um filho; o luto pela impossibilidade biológica de concebê-lo; a escolha de uma forma, dentre várias, para realizar esse desejo; e a relação com um terceiro sujeito que viabiliza a vinda do filho. Ao final da discussão teórica, a autora sugere o enfrentamento rigoroso das teorias, pois afirma que elas são insuficientes para dar conta das profundas transformações nas famílias, sobretudo em seus enredamentos afetivos. 
O artigo "Homoparentalidade: novas luzes sobre o parentesco" (FONSECA, 2008) revisita diferentes elementos da noção de "Família que Escolhemos", a partir do trabalho de Kath Weston e outras antropólogas que pesquisam principalmente nos Estados Unidos e na Inglaterra. Nele se ressalta o quanto certos casais lésbicos, recorrendo às novas possibilidades legislativas e tecnológicas, recriam as ideologias de parentesco. Esse estudo teórico aponta que a homoparentalidade, assim como outras formas familiares contemporâneas, são vistas como co-produções que envolvem - além de valores culturais - lei, tecnologia e dinheiro.

$\mathrm{O}$ artigo, da área da Comunicação, "O direito à homoparentalidade em duas novelas da TV Globo: relendo os casais de lésbicas e de gays em Senhora do Destino e Páginas da Vida" (FERNANDES, 2013) reflete sobre o direito à homoparentalidade apresentado nas duas telenovelas citadas em seu título. Para isso, foi realizada uma reflexão sobre a opinião de alguns estudiosos de sexualidade e aplicadas essas considerações aos casais Jenifer e Eleonora e Marcelo e Rubinho das respectivas telenovelas. $\mathrm{O}$ autor chega às conclusões de que a homoparentalidade é um direito a ser conquistado pelos homossexuais e que as atitudes dos personagens deram subsídios para a reflexão social sobre a temática. Também considera que a narrativa teleficcional assume um papel na formação pública ao pautar assuntos pouco debatidos em outros espaços, como jornais e telejornais.

Dois artigos que problematizam a questão da homoparentalidade no contexto escolar são "Discutindo valores na escola: homoparentalidade e novos conceitos de família" (FREITAS; DIAS, 2012) e "Os sentidos e os significados produzidos pela escola em relação à família homoparental: um estudo de caso" (CADETE; FERREIRA; SILVA, 2012). O primeiro é decorrente de uma pesquisa que visou a entender quais aspectos e valores são mais relevantes na criação da família, ressaltando os níveis de aceitação dos divergentes formatos encontrados atualmente para alunos de turmas de ensino médio de escolas estaduais do município de Natal/RN. Para isso, os autores utilizaram questionários e grupos de debate. Ao final do estudo, apontam que, tanto o conceito de família quanto a atual predisposição à formação familiar têm sofrido alterações significativas, visto que o ideal de constituição familiar não está mais arraigado aos laços sanguíneos, o que permite a aceitação, vista pelos autores como ainda sutil, de novas unidades familiares baseadas em valores morais e laços afetivos (FREITAS; DIAS, 2012). O segundo buscou investigar quais os sentidos e significados produzidos pelos atores da escola em relação à família homoparental. As autoras realizaram entrevistas livres com dezesseis representantes dos vários segmentos de uma escola pública, de Recife-PE, sendo eles cinco professores do Ensino Fundamental, cinco alunos, um coordenador, diretor e vice-diretor, uma merendeira, um porteiro e um profissional dos serviços gerais. A partir dessa pesquisa identificou-se que o conceito de família está atrelado à configuração nuclear e que a homoparen- talidade não é, na maioria das vezes, pensada como família e nem discutida nesse espaço educativo (CADETE; FERREIRA; SILVA, 2012).

Todas as publicações em questão apontam para a necessidade de mudança do paradigma ainda atual sobre a homoparentalidade, carregado de preconceitos e estigmas. Ainda que se possa verificar, em alguns artigos, uma discussão que interliga mais de um campo de conhecimento é necessária a reflexão interdisciplinar para que se entenda o processo como um todo.

\section{Considerações finais}

A partir do levantamento e análise das publicações utilizadas como base para este estudo, podemos verificar o quanto é recente e incipiente a discussão sobre a temática da homoparentalidade no Brasil, mostrando-se como um campo potencial de produção científica. Mesmo que se possa perceber um aumento de estudos nessa área ao longo dos últimos anos, ainda são escassas as produções científicas desse tema no país. Consideramos que a baixa produção vinculada à homoparentalidade está relacionada ao fato de o próprio termo ter sido cunhado em termos históricos recentes, em 1986, e num contexto de uma associação social para famílias e futuras famílias homoparentais na França. Nesse sentido, pontuamos que historicamente o termo é novo e parece ter adentrado o campo científico brasileiro quase vinte anos após a sua inserção através da APGL. Sendo uma nomenclatura que desponta recentemente no cenário científico, são necessários mais estudos para o avanço das compreensões acerca da temática.

Analisando os resultados das pesquisas existentes, percebemos que o tema em questão ainda é muito cercado por preconceitos, rótulos e estigmas. Ainda que esteja ganhando mais visibilidade social e, com isso, maiores discussões a respeito das novas configurações familiares e a própria homoparentalidade, o que vemos reinando nos discursos sociais e em certa medida, no campo da ciência, é o modelo de família heterocêntrico. Esperamos que o presente estudo contribua para uma reflexão a respeito da importância e da atualidade do tema no que diz respeito à necessidade de novas pesquisas relacionadas. Além disso, sugerimos pesquisas interdisciplinares sobre a temática, levando em consideração o ser humano como sujeito individual, social, cultural e político.

\section{Referências}

ASSOCIATION DES PARENTS ET FUTURS PARENTS GAYS ET LESBIENS. 2017. Disponível em: https://www.apgl. fr. Acesso em: 8 set. 2017.

ARAÚJO, L. F.; OLIVEIRA, J. S. C. A adoção de crianças no contexto da homoparentalidade. Arquivos Brasileiros de Psicologia, v. 60, n. 3, p. 40-51, 2008.

BRANDÃO, D. V. C. Parcerias homossexuais: aspectos jurídicos. São Paulo: Revista dos Tribunais, 2002.

CADETE, V. G.; FERREIRA, S. P. A.; SILVA, D. B. Os sentidos e os significados produzidos pela escola em relação à família homoparental: um estudo de caso. Interação em Psicologia, v. 16, n. 1, p. 101-112. 2012. Cross ${ }^{\text {Ref }}$ 
CECILIO, M. S.; SCORSOLINI-COMIN, F.; SANTOS, M. A Produção científica sobre adoção por casais homossexuais no contexto brasileiro. Estudos de Psicologia, Natal, v. 18, n. 3, p. 507-516. jul./set. 2013. Cross ${ }^{\mathrm{Ref}}$

CONSELHO FEDERAL DE PSICOLOGIA. Resolução CFP $n^{\circ}$. 001/99. Estabelece normas de atuação para os psicólogos em relação à questão da Orientação Sexual. 1999. Disponível em: $\quad$ https://site.cfp.org.br/wp-content/uploads/1999/03/ resolucao1999 1.pdf. Acesso em: 16 out. 2015.

COSTA, H. S.; FILHO, F. E. L. A união homoafetiva e sua regulamentação no Brasil. Revista Jus Navigandi, Teresina, ano 20, n. 4361, 2015. Disponível em: http://jus.com.br/ artigos/39874. Acesso em: 21 jul. 2015.

CUSTÓDIO, J. Homoparentalidade: um direito em construção. Espaço Jurídico: Journal of Law, v. 13, n. 1, p. 91-100. jan./ jun. 2012. Disponível em: http://editora.unoesc.edu.br/index. php/espacojuridico/article/view/1426. Acesso em: 15 jan. 2015

FARIAS, M. O. Mitos atribuídos às pessoas homossexuais e o preconceito em relação à conjugalidade homossexual e a homoparentalidade. Revista de Psicologia da UNESP, v. 9, n. 1, p. 99-109, 2010. Disponível em: http://seer.assis.unesp.br/ index.php/psicologia/article/download/431/410. Acesso em: 13 jan. 2015

FERNANDES, G. M. O direito à homoparentalidade em duas novelas da TV Globo: relendo os casais de lésbicas e de gays em Senhora do Destino e Páginas da Vida. Revista Comunicação, Cultura e Sociedade, v. 2, n. 1, 2013. Disponível em: https:/ periodicos.unemat.br/index.php/ccs/issue/viewFile/RCCS\%20 2/25. Acesso em: 17 fev. 2014.

FERNANDES, R. M. A representação da homossexualidade nos discursos jurídicos sobre adoção homoparental. Cadernos de Campo, São Paulo, v. 22, n. 22, p. 250-261. 2013. Cross ${ }^{\text {Ref }}$

FERREIRA, N. S. A. As pesquisas denominadas "estado da arte". Educação \& sociedade, Campinas, v. 23 , n. 79 , p. 257 272. 2002. Cross ${ }^{\mathrm{Re}}$

FONSECA, C. Homoparentalidade: novas luzes sobre o parentesco. Estudos Feministas, Florianópolis, v. 16, n. 3, p. 769-783, dez., 2008. Cross ${ }^{\text {Ref }}$

FOUCAULT, M. Microfisica do poder. Rio de Janeiro: Graal, 1996.

FREITAS, L. R. M. de; DIAS, R. L. Discutindo valores na escola: homoparentalidade e novos conceitos de família Quipus, Natal, v. 1, n. 2, p. 101-107, jun./nov. 2012. Disponível em: $\quad$ https://repositorio.unp.br/index.php/quipus/article/ view/154/172. Acesso em: 18 fev. 2014.

FUTINO, R. S.; MARTINS, S. Adoção por homossexuais: uma nova configuração familiar sob os olhares da psicologia e do direito. Aletheia, Canoas, n. 24, p. 149-159. jul./dez. 2006. Disponível em: http://pepsic.bvsalud.org/scielo. php?script=sci arttext\&pid=S1413-03942006000300014 Acesso em: 20 fev. 2014.

MARTINEZ, A. L. M. Famílias homoparentais: tão diferentes assim? Psicologia em Revista, Belo Horizonte, v. 19, n. 3, p. 371-388, dez., 2013. Disponível em: http://periodicos. pucminas.br/index.php/psicologiaemrevista/article/view. P.1678-9563.2013v19n3p371/6210. Acesso em: 12 fev. 2015.

MEDEIROS, C. P. Uma família de mulheres: ensaio etnográfico sobre homoparentalidade na periferia de São Paulo. Estudos Feministas, v. 14, n. 2, p. 535-547, maio/ago. 2006. Cross ${ }^{\text {Ref. }}$
PASSOS, M. C. Homoparentalidade: uma entre outras formas de ser família. Psicologia Clínica, Rio de Janeiro, v. 17, n. 2, p. 31-40, 2005. Cross ${ }^{\text {Ref }}$

PERELSON, S. A parentalidade homossexual: uma exposição do debate psicanalítico no cenário francês atual. Estudos Feministas, v. 14, n. 3, p. 709-730, set./dez. 2006. Cross ${ }^{\text {Ref. }}$

RODRIGUEZ, B. C.; GOMES, I. C. Novas formas de parentalidade: do modelo tradicional à homoparentalidade. Boletim de Psicologia, São Paulo, v. 62, n. 136, p. 29-36, jun. 2012. Disponível em: $\quad$ http://pepsic.bvsalud.org/scielo.php?script=sci arttext\&pid=S0006-59432012000100004. Acesso em: 10 fev. 2015.

RODRIGUEZ, B. C.; PAIVA, M. L. S. C. Um estudo sobre o exercício da parentalidade em contexto homoparental. Vínculo - Revista do NESME, v. 1, n. 6, p. 1-111, jun. 2009. Disponível em: $\quad$ http://pepsic.bvsalud.org/scielo.php?script=sci arttext\&pid=S1806-24902009000100003. Acesso em: 16 jan. 2015 .

ROUDINESCO, E. A família em desordem. Rio de Janeiro: J. Zahar, 2003

RUIZ-OLABUÉNAGA, J. I. Metodología de la investigación cualitativa. Bilbao, España: Universidad de Deusto, 2003.

SANTOS, C.; BRUNS, M. A. T. A homoparentalidade em questão: a voz de gays e lésbicas com filhos. Revista da Abordagem Gestáltica, v. 12, n. 2, p. 89-108. jul./dez., 2006. Disponível em: http://www.redalyc.org/articulo. oa? id=357735505007. Acesso em: 12 jan. 2015 .

SOUZA, É. R. de. Papai é homem ou mulher? Questões sobre a parentalidade transgênero no Canadá e a homoparentalidade no Brasil. Revista de Antropologia, São Paulo, v. 56, n. 2, p. 397-430, 2013. Disponível em: https://www.revistas.usp.br/ra/ article/view/82527/85502. Acesso em: 9 fev. 2015.

VILHENA, J. et al. Que família? Provocações a partir da homoparentalidade. Revista Mal-estar e Subjetividade, Fortaleza, v. 11, n. 4, p. 1639-1658, dez., 2011. Disponível em: $\quad$ http://pepsic.bvsalud.org/scielo.php?script=sci arttext\&pid=S1518-61482011000400014\&lng=pt\&nrm=iso. Acesso em: 11 abr. 2014

ZAMBRANO, E. et al. $O$ direito à homoparentalidade: cartilha sobre as famílias constituídas por pais homossexuais. Porto Alegre: Venus, 2006.

Recebido em: 22 de outubro de 2015 Acesso em: 20 de outubro de 2017 